\title{
LA CIENCIA DOCUMENTAL COMO GARANTÍA DE LA VERDAD PERIODÍSTICA
}

\author{
Antonio Parra Pujante* \\ Facultad de Comunicación y Documentación. Universidad de Murcia.
}

\begin{abstract}
Resumen: En mitad del bosque de datos y de información que los nuevos medios informativos y tecnologías de la comunicación han traído al mundo globalizado actual, el periodismo tradicional y de calidad emerge como garantía de verificación y reflejo científico y objetivo de la realidad. Sin embargo, para ello, necesita un plus de precisión que, entre otras, pueden proporcionarle las herramientas de la documentación, ciencia que, a la vez, resuelve sus problemas gnoseológicos y facilita su estatuto epistemológico. Lo que sigue es un primer esbozo de epistemología de la documentación que necesitará en el futuro un mayor desarrollo en diálogo interdisciplinar.
\end{abstract}

Palabras clave: información; documentación; precisión; objetividad; verdad.

\section{Title: DOCUMENTARY SCIENCE AS A GUARANTEE OF THE TRUTH IN JOURNALISM.}

Abstract: In the middle of the forest data and information that new media and communication technologies have brought to the globalized world, traditional journalism and quality emerges as collateral verification and scientific and objective reflection of reality. However, for this you need a precision plus, among others, can provide the tools of information science, a science that, in turn, solves problems cognitive and facilitates epistemological status. What follows is a first draft of epistemology of documentation needed in the future further development interdisciplinary dialogue.

Keywords: information; documentation; accuracy; objectivity; truth.

\section{INTRODUCCIÓN}

Poner frente a frente periodismo y literatura, como a veces se hace, para concluir que son dos ramas de una misma actividad, o, por el contrario, para marcar límites y diferencias entre ambas disciplinas, es ya un antiguo lugar común en el debate gnoseológico, porque, después de todo, lo que se dirime en esa persistente querella no es, en última instancia, más que una teoría del conocimiento, y en su ángulo más extremo: una teoría de la verdad.

De lo que se trata, en definitiva, aunque el debate no se produzca habitualmente de manera expresa en estos términos, es de averiguar en qué medida lo que dice el periodismo es verdad (Parra Pujante, 2002, 2003), hasta dónde sus descripciones son, al

*aparra@um.es

Recibido: 02/02/2012; $2^{\text {a }}$ versión: 21/05/2012; 3ª revisión: 02/07/2012; aceptado: 05/07/2012.

PARRA PUJANTE, A. La ciencia documental como garantía de la verdad periodística. Anales de Documentación, 2012, vol. 15, no 2. ISSN: 1697-7904. http://dx.doi.org/10.6018/analesdoc.15.2.140832. 
menos en hipótesis, una realidad objetiva que el informador encuentra en el mundo de manera verificable. $Y$, en consecuencia, si la pretensión de todo periodista es describir la realidad 'tal cómo es', en qué medida la literatura posee esa misma capacidad de ser eco escrito de la realidad. Aquí, ya que no es nuestro objeto de estudio, no vamos a entrar a analizar la posible capacidad emocional de la literatura, o del arte en general, para hablarnos de una verdad más honda -en sentido emocional o psicológico- que la buscada por la ciencia. Vamos a situar, por el contrario, el ejercicio de la información periodística por los medios o canales que sean- en el mismo territorio en que se mueve la ciencia en cuanto a su capacidad de llevar a cabo descripciones verificables y, en su caso, verídicas y plausibles de la realidad. Y en este recorrido averiguaremos que la Ciencia Documental jugará para el Periodismo el papel de "testigo" y de evidencia, lo que procurará a este un estatuto epistemológico que convertirá su actividad en sólida y veraz, homologable a cualquier otra que intente ser reflejo de la realidad.

La hermenéutica de textos en el campo de la epistemología, confrontados a los usos profesionales de los periodistas, me llevará a una serie de conclusiones por el momento provisionales.

\section{UN ESTATUTO EPISTEMOLÓGICO}

Frente a la mala prensa que tiene actualmente la prensa (valga la redundancia paradójica), y ello por distintas circunstancias que ahora no vienen al caso, aquí vamos a mantener que, bajo determinadas condiciones, el periodismo sí tiene capacidad de decir verdad. Algunas de esas necesarias condiciones son de orden ético o deontológico, de las que, por razones obvias, dado el campo de nuestra investigación en este artículo, no nos vamos a ocupar. Sin embargo, como teóricos de la información y/o documentalistas, sí tenemos algo que decir sobre métodos orientados a que el camino de la información periodística no se desvíe demasiado de la senda científica.

Y es justo ahora cuando podemos añadir que en ese empeño el documentalismo y sus profesionales tienen mucho que aportar, y de hecho cada vez es más fuerte el reconocimiento de que el documentalista es algo más que un auxiliar del informador en el espacio de una redacción de cualquier medio. Hoy se acepta -incluso en los espacios más o menos endogámicos del periodismo activo - que documentalismo y periodismo están mucho más cerca de lo que pensaban los informadores. Es más, lo que desde los años sesenta del siglo XX se conoce como periodismo de precisión -que engarza con el periodismo tradicional de investigación, pero que lo supera -, cuyos métodos muy lentamente comienzan a introducirse en España, está en la base del nuevo periodismo que, para ser verdaderamente preciso, es decir, objetivo, ha de contar con las actuales tecnologías de la información y con el manejo fluido de las fuentes documentales, para así no depender sólo de las tradicionales fuentes periodísticas, como las políticas o gremiales, frecuentemente interesadas y, por decirlo con jerga periodística, intoxicadoras. Dicho esto se entiende que en los medios estadounidenses desde hace años se venga trabajando en equipos formados por documentalistas, informáticos y periodistas, aunque en España, y en 
general en Europa, sea todavía, en parte, una aspiración que incluso empeora sus expectativas con la crisis general de la prensa tradicional y los menguantes recursos en ventas e ingresos por publicidad.

Sin embargo, frente a la tentación de ver esas disciplinas como un enemigo de la prensa tradicional, ésta debería aprovecharlas como necesarias socias y compañeras de viaje hacia un periodismo de calidad, el único, en todo caso, que podrá resistir frente al irreversible avance de los nuevos canales informativos (Internet, móviles), como vienen mostrando desde hace años los estudiosos del campo (Aguado y Martínez, 2009).

Al desarrollar esta investigación partimos de la base de que el periodismo pertenece a la raíz judía de la verdad (que más adelante describiremos), es decir, necesita confianza ajena para tener crédito, mientras que la Ciencia Documental podría ser adscrita a una raíz griega que engarza con la verdad como adecuación (adaecuatio intellectus et rei, coincidencia entre el entendimiento y la realidad), que la hace más objetiva, y que entre las teorías del conocimiento actuales podríamos situar dentro de la denominada verdad como correspondencia. Sin embargo, con el apoyo del documentalismo, el periodismo podrá al final engarzar con una teoría de la verdad similar, reivindicando así su propio estatuto epistemológico, su carácter científico y razonablemente objetivo.

Y ello al margen de que, siendo pragmáticos, aceptemos que la paupérrima realidad mediática actual haga difícil una permanente conjunción de ambas disciplinas. En cualquier caso, no se trata aquí de resolver problemas concretos o de ofrecer soluciones al quehacer profesional de periodistas y documentalistas, sino de señalar, en una primera aproximación desde la teoría del Conocimiento, ese papel cognitivo que la documentación presta al periodismo.

\section{UN POCO DE HISTORIA}

Con su aparición en Europa el periodismo aportaba una manera radicalmente distinta de afrontar lo público y lo privado. El periodismo nacía como institución de una nueva sociedad que desembocaría en la Ilustración, en un nuevo mundo, por decirlo a la manera de Weber, desencantado, que además se despedía de los viejos dioses para pedir a los hombres que se atrevieran a saber y a valerse de su razón como única guía. Una sociedad que quería dejar de regirse por los dogmas de la teología para dar paso a la política, a la moral pública y al impulso racional de los ciudadanos libres y maduros (en el ideal ilustrado) necesitaba de este nuevo género que abría una ventana a la visibilidad de lo que hasta entonces había permanecido en el terreno de lo privado (Habermas, 1994); de otro lado, la nueva disposición de una mayor cercanía al ciudadano, una relación menos aurática de la parte de los gobernantes exigía esa dimensión mediática de lo público a través de la cual los nuevos habitantes de las naciones exigían cuentas a sus gobiernos. Pero, en su nacimiento, el periodismo fue una actividad todavía poco profesionalizada, practicada sobre todo por escritores, y en cuya actividad se conjugaban desde los elementales noticiarios sobre asuntos lejanos y curiosos a textos puramente literarios. 
A lo largo del siglo XIX -pese a su carácter más fuertemente ideológico- y especialmente durante el pasado siglo XX, el periodismo se profesionalizó totalmente, las empresas mediáticas se convirtieron -al margen del carácter ideológico que algunas de ellas pudieran conservar - en empresas sin más, en las que primaba el negocio. Pero para el debate que aquí nos reclama vamos a recordar, en un inevitable salto dadas las características de este trabajo, que fue a partir de la Primera Guerra Mundial cuando los periodistas y estudiosos de la comunicación mediática comenzaron a preguntase con insistencia si la objetividad es una meta deseable, e incluso posible, para los informadores. De esa época es un texto clásico en la defensa de la objetividad periodística, defensa llevada a cabo con un carácter casi fundamentalista por Walter Lippman (1922). Para Lippman, los símbolos son producto de las emociones y, consecuentemente, poco dignos de confianza. De la misma manera considera que las necesidades y los deseos participan de la construcción de la realidad y se entremeten en la visión pura. La objetividad no es para él una idea noble pero inalcanzable, sino que se trata de separar con nitidez las cosas reales de las fabricadas o construidas. El ideal es ver las cosas con ojos vírgenes, libres de todo símbolo y de todo interés.

El sociólogo americano trasladó su evidente platonismo a la actividad mediática. Pensaba Lippman que el ciudadano obtenía su conocimiento de los medios de comunicación, por lo que pedía a los periodistas esa mirada distante, absolutamente objetiva. Y citaba abiertamente al Platón del mito de La Caverna para comparar las sombras que veían los encadenados del relato, y que confundían con la verdadera realidad, con el reflejo de la realidad que realizaban los medios, una realidad para él falsa o poco cercana a la verdad.

\section{PERIODISMO DE PRECISIÓN}

Muy recientemente, durante los años sesenta del siglo XX, dos movimientos, opuestos en su idea de periodismo y en sus pretensiones formales, surgieron, curiosamente, bajo la misma denominación: 'New Journalism'. Bajo esa denominación concurrían tanto las investigaciones de Philip Meyer (1973 y 1993) como ese movimiento abanderado por escritores como Tom Wolfe. En realidad se trataba de propuestas situadas en las antípodas. El tipo de crónica ofrecida por Wolfe y otros autores como Jimmy Breslim intentaba colorear el relato a través de un estilo literario y subjetivo, que con el tiempo incluso llevó a sus seguidores a poner más retazos de ficción, de realidad inventada, que de relato personal de un determinado suceso. La posible confusión llevó a Meyer a dejar de hablar de nuevo periodismo para referirse a sus propuestas bajo la denominación de periodismo de precisión (Precision journalism), o bien "nuevo periodismo de precisión". Lo que Meyer pretendía era dar a los profesionales de la información las herramientas metodológicas e investigadoras ya utilizadas con éxito durante décadas por las llamadas ciencias sociales.

"Por eso - escribe Dáder en la introducción a la edición en castellano de la obra de Meyer-, como el propio Meyer deja claro en sus páginas, el periodismo de precisión no 
guarda ninguna relación con los problemas de los géneros y los especialistas académicos de la redacción periodística. Tiene en cambio mayor contacto con el periodismo de investigación, aunque, como también se verá, no puede sin más confundirse con él, siendo en todo caso un instrumento sistemático de trabajo para superar la, a menudo, intuitiva, voluntarista y desorganizada actividad del periodismo investigador".

Meyer piensa, en el extremo contrario de lo que sería una reivindicación del periodismo como literatura, que la actividad de informar sobre hechos concretos, la actividad periodística, puede y debe ser ciencia, a condición de que los profesionales adquieran y practiquen una serie de protocolos comunes a toda investigación científica. Esquemas, cuadros, estadísticas, sondeos de opinión, utilización de archivos, documentos, métodos apropiados de aproximación al hecho, etcétera, servirían para desvelar la esencia de unos hechos que permanecen ocultos no siempre porque los cubra un velo perverso e interesado de impunidad -aunque eso también pueda ocurrir-, sino por incapacidad de los profesionales para utilizar la más certera de las aproximaciones. En la última revisión de sus ideas, llevada a cabo en los años ochenta, Meyer incluye en sus propuestas las nuevas tecnologías de la información, la informática, que viene a potenciar la capacidad investigadora del periodista. El antiguo profesional de la información y posteriormente profesor universitario, rechaza dos tradiciones clásicas del periodismo: la pasividad y la inocencia, es decir, la creencia de que el periodismo debe contar noticias, no crearlas, de un lado, y la convicción, de otro lado, de que el periodista ha de aplicar una mirada inocente a la realidad, sin estar ésta condicionada por una excesiva especialización.

Efectivamente, como hemos escrito en otros lugares (Parra Pujante, 2002 y 2003), el periodista suele creerse en un lugar de privilegio desde el que mirar la realidad: siente que todo lo que refleja en su medio es por principio la objetividad, aunque publique una evidente mentira. Ello es así porque, aun cuando reproduzca, por ejemplo, las declaraciones de un político en las que éste miente sobre cualquier cuestión de su responsabilidad, lo que el periodista lleva al medio es una verdad objetiva: el hecho mismo de que ese político ha hecho unas determinadas declaraciones. De lo que se responsabiliza el periodista es de esa verdad primera, las declaraciones del político o de cualquier otra fuente, que son reales $y$ no inventadas por el informador, independientemente de que sea cierto o no lo que haya declarado la fuente. Otra cosa es que desde una instancia posterior - la normativa o ética - el periodismo también pueda y deba llamar la atención sobre el carácter mentiroso del político que hizo esas declaraciones, pero desde una instancia simplemente epistémológica el periodismo ha reivindicado tradicionalmente su posición "inocentemente" objetiva. Se trata de un sentimiento muy extendido entre los profesionales de la información, que hemos llamado "síndrome de la reina Isabel", un concepto tomado de Latour, quien habla en términos parecidos al presentar la lógica de la actividad científica, pues la ciencia, al describir el mundo, cree hacerlo desde la distancia exquisitamente indiferente, o bien con la misma protocolaria convicción con que la reina de Inglaterra lee el discurso preparado por el gobierno ganador de unas elecciones, sea éste laborista o conservador. (Parra, 2002, 2003). 
Meyer rechaza esta posición, no porque el periodista no deba intentar ser objetivo, y procurar no inventar noticias, más bien todo lo contrario, sino porque el autor estadounidense cree que, siguiendo unas adecuadas normas, el periodista no sólo no inventa nada, sino que hace visible una realidad que de otra manera, sea por ignorancia, pereza o interés del poder, permanece oculta a los ciudadanos, que celebrarán ese descubrimiento de una realidad que no por ser desconocida dejaba de existir: muchas veces esa verdad, incluso política o socialmente escandalosa, está ahí, en un polvoriento o informatizado archivo, en un documento olvidado o en el mero cruce de datos en la pantalla de un ordenador.

\section{ALGUNOS OBSTÁCULOS}

Naturalmente, contra Meyer se pueden decir algunas cosas, no sería difícil plantearle algunas objeciones a un método que se ha extendido en escuelas de periodismo y redacciones de Estados Unidos, pero que apenas comienza a ser conocido y aplicado en Europa. Una de esas objeciones, no banal, es la de las murallas legales que algunos países, entre ellos España, establecen para mantener a salvo de la curiosidad pública documentos que son de interés común, una actitud, por cierto, contra la que los periodistas y documentalistas estadounidenses dieron una fuerte batalla en los años setenta, con los resultados, si no perfectos, sí al menos muy aceptables. Lo curioso es que en España, un prejuicio procedente de la izquierda y de determinados movimientos sociales, defienden la impunidad documental bajo el tópico o el principio de la salvaguarda de la intimidad, pretexto bajo el cual los distintos gobiernos suelen trazar un limes opaco ante cualquier intento de investigación. Como ha recordado Dáder (1997) con acierto, en España siguen siendo secretas desde las declaraciones de Hacienda hasta los datos registrados en el carné de conducir o en el pasaporte, sólo accesibles a los funcionarios que custodian los ficheros o a los jueces si realizan un auto de intervención. Aunque las quejas de Dáder tienen más de una década, en lo esencial, el panorama sigue siendo hoy el mismo y muchos políticos se aprovechan de ello para actividades corruptas. Aunque en el momento de cerrar este artículo hay en marcha un proyecto de Ley de Transparencia que tal vez pueda cambiar las cosas en el futuro.

Para Dáder resulta llamativo que nuestra legislación prohíba o sea tan cicatera con el derecho de acceso a dicha información de propiedad pública. Pero es aún más sorprendente que ningún periodista español esté reclamando la inmediata supresión de una legislación que impide al conjunto de los ciudadanos tener noticia de algo que significa un daño para el conjunto de todos ellos. El argumento subyacente y dominante en España es que existe una obligación absoluta de preservar el honor o la buena imagen de los imputados por la Administración mientras no existan sentencias judiciales condenatorias.

Dáder (1997) recuerda un caso, ya algo lejano, en que la defensa a ultranza de la privacidad y el honor de esquilmadores reales de los bienes provocaron situaciones casi cómicas: así, en el otoño de 1993, diversas informaciones periodísticas revelaron que un ministro del gobierno español y su familia habían realizado diversos viajes "gratis total" 
en los barcos de la empresa pública 'Transmediterránea'. Cuando el director de la compañía intentó contrarrestar las críticas surgidas por dicho trato de favor, ese responsable argumentó que muchos otros políticos y personajes públicos $-\mathrm{y}$ no sólo el ministro denunciado - recibían en concepto de "atención" ese regalo de billetes gratuitos. Y cuando los periodistas reclamaron entonces la lista de todos los beneficiarios de tales favores otorgados a costa del presupuesto público, el directivo de la compañía marítima zanjó la cuestión diciendo que no tenía derecho a revelar esos nombres porque ello pondría en peligro, en algunos casos, la tranquilidad conyugal de algunos de los favorecidos -que habían viajado con acompañante inhabitual -, y eso significaría "un atentado inconstitucional contra su intimidad". Ante lo cual, nuestros periodistas dieron una vez más muestras de su inmoderada pleitesía a dicho principio y ya no osaron volver a exigir la revelación de dicho listado. Ningún comentarista en los medios de comunicación fue capaz de replicar a semejante argumento y recordar que la inspección del uso dado a los recursos públicos no puede detenerse por el asunto - ese sí verdaderamente privado -, de lo que haya de aclarar con su esposa o esposo quien ilícitamente haya utilizado unos fondos públicos.

Algunas situaciones o espacios opacos denunciados por Dáder han cambiado afortunadamente, y hasta cierto punto también la actitud de la prensa (cabe pensar en algunos casos de corrupción que han emergido recientemente y que han sido sacados a la luz pública por los medios, pero, en conjunto -a la espera de esa nueva Ley de Transparencia- las cosas siguen igual en lo esencial.

\section{EL PAPEL CENTRAL DE LA DOCUMENTACIÓN}

El periodismo, con este tipo de métodos de investigación documental, trata también de subrayar su naturaleza científica, y por lo tanto su capacidad de describir objetivamente la actualidad, la realidad que pasa ante nuestros ojos cada día. Y en ese empeño, los documentalistas han de ser, no meros colaboradores, sino compañeros de viaje de los periodistas con la misma decisiva importancia.

El papel esencial del documentalista en el campo de la información periodística ha sido muy bien subrayado por Jorge Moreno Matos (2006) con un ejemplo cinematográfico que deseo reproducir aquí por su significado:

A todo aquel que se pregunte en qué consiste el trabajo en el archivo de un diario $o$ de un medio de comunicación cualquiera, puede resultarle interesante la siguiente historia: A un costo asombroso de casi 100 millones de dólares, en 1998 la película Impacto Profundo atraía grandes cantidades de público a las salas de cine del mundo entero. La película, como muchos recordarán, cuenta de manera casi verosímil la ficción de un asteroide gigantesco a punto de chocar con la tierra. En una escena de ésta, cuando el presidente de Estados Unidos explica al mundo la razón de la inevitable tragedia, se arma un alboroto tremendo en la sala de redacción de un canal de noticias. Hay un instante brevísimo en esta parte de la película, cuando el presidente pronuncia la palabra "asteroide", en que una 
periodista grita exasperada: "¿De qué tamaño fue el meteorito que mató a los dinosaurios?".

Y concluye el autor:

Resulta frustrante constatar, una vez más, cómo para la gran mayoría del público (y cada vez con mayor y alarmante frecuencia entre jóvenes periodistas) pasa inadvertido por completo un detalle aparentemente insignificante: lo que está haciendo la periodista de manera tan desesperada es demandar información al personal del centro de documentación sobre el asteroide de diez kilómetros de diámetro que se estrelló en lo que hoy es México y que la huella de su choque hace 65 millones de años, el "impacto profundo" de la película, formó lo que ahora conocemos como el cráter Chicxulub de 200 kilómetros de diámetro en la Península de Yucatán.

En realidad -recuerda Jorge Moreno Matos (2006)- "la historia va más allá de la anécdota”, pues para hacer la película, los productores, al igual que la periodista, acudieron a los expertos en información, además de a otros, para documentarse sólidamente y hacer creíble la historia. Y es que, como insiste el autor, en la actualidad no existe actividad humana que no requiera de información, aunque sea en su mínima expresión, para ser llevada a cabo eficientemente. "Como estos -continúa - hay decenas de ejemplos, como las hay de preguntas que a diario resuelven los responsables de las unidades de información de empresas, instituciones, centros de enseñanza, etc. y, claro está, las de periódicos, revistas, radios, televisoras. Esa es la razón de nuestro trabajo".

"Hoy no basta con tener los datos más extraordinarios, escurridizos o insólitos para convertir la información en un recurso estratégico, que es la verdadera naturaleza de la información." Y no basta porque hay millones de ellos. Cómo acceder y cómo administrarlos para sacar provecho de tan inmensa red de impactos, "es la misión del documentalista" en nuestra época. En otras palabras, resume Moreno: "Saber enfrentar el 'aluvión informativo' y no sucumbir ante la 'infoxicación' - de la que habla Alfons Cornella- es el verdadero desafío que enfrenta el documentalista de prensa en la actualidad".

Pero también a la inversa: "El conocimiento de las técnicas documentales ha dejado de ser un terreno exclusivo del documentalista o del experto en Documentación para convertirse en una de las herramientas más eficaces para el profesional de la Información y la Comunicación" (López Hernández, 2000 y 2001), pues ya no tiene cabida el profesional mal documentado (indocumentado).

Pero esas técnicas y herramientas las da al informador el documentalista, por lo que la documentación "debe dejar de verse por nosotros mismos, los profesionales de la información” (López Hernández, 2000 y 2001), como algo alejado de las Ciencias de la Comunicación.

Es sabido que el ruido no es información, sino más bien lo que la entorpece, algo que sabemos al menos desde Shannon y su teoría matemática, y que un exceso de información 
produce ruido, un bosque de datos caóticos, imposible de organizar, que impide una transmisión nítida y, consecuentemente, la verdadera comunicación. Es algo que tuvo claro González Antón (2009) al elaborar su guía, aunque con el referente básico de los medios canarios. "El trabajo -explica- responde a la necesidad de generar instrumentos de recuperación de la información dado el gran volumen de la misma y a su forma, muchas veces caótica y desorganizada de presentación".

\section{DOS PROBLEMAS QUE RESUELVE LA DOCUMENTCIÓN}

Junto al problema, no menor, de idealización platónica que sufre la mirada hacia sí mismo del profesional de la información periodística, descrita en los anteriores epígrafes, el periodismo, en su práctica real y sin mitos, padece otros dos problemas, a saber:

a) Su criterio de objetividad resulta excesivamente procedimental (Tuchman, 1983 y 1999), es decir, se piensa en el seno de la profesión que basta con seguir un determinado protocolo para que lo que resulte (lo que se publica) sea completamente objetivo y verdadero. Además de que, en ese procedimiento rutinario, se da un excesivo crédito a las fuentes oficiales frente a otras.

y b) Su raíz de la verdad coincide con una de las grandes raíces de la verdad, tal como las clasifica la moderna teoría del Conocimiento, en concreto, con la de procedencia judía, que se basa en la confianza (emunah) en algo o en alguien, por ejemplo, en el caso de la tradición hebrea, en el cumplimiento de la llegada, un día, del Mesías. Y esto es así porque la profesión periodística fía su crédito a la confianza del usuario de la información: crédito en la determinada opinión de un medio (comentarios editoriales), en la opinión y análisis de sus comentaristas y analistas y en las simples informaciones, pues ningún usuario puede por su cuenta verificar cada noticia del medio, de manera que no le queda más remedio que creer en lo que este le cuenta, tiene que confiar en que no le engañan ni le mienten.

Las consecuencias de estos dos problemas resultan nefastas epistemológicamente, pues pueden contaminar irremediablemente la objetividad y la verdad de los enunciados periodísticos. Y además, con frecuencia están en la base de que los medios hayan sido situados en el plano de la "sospecha" por los filósofos del conocimiento y por el público en general, y que queden clasificados a veces como meros cancerberos del statu quo. ¿Cómo resuelve la Ciencia Documental estos problemas, convirtiéndose consecuentemente en el fuste epistemológico de la información mediática? Dando la base documental que precisa toda información cuando necesita estar avalada por fuentes grises documentales, textos o imágenes. En resumen: haciendo de testigo cognitivo. Después del siglo XVIII la ciencia reivindicó la necesidad de convertir en objetiva la experiencia subjetiva a través del testigo (Moscoso, 2001, p. 127-137). En este proceso genuinamente epistémico, el documentalista sería propiamente el testigo, mientras que los materiales con los que trabaja (su campo material) serían la evidencia, la prueba que verifica lo escrito o lo dicho por el informador. En conclusión: la huella.

Claro que el documentalista, como el archivero, para cumplir con este papel y con el que se le atribuye en general no está libre de responder a las exigencias deontológicas y a 
la veracidad en su labor, a la vez que ha de tratar de escapar a la mano del poder, o al poder del sistema, que trata de establecer a veces unos criterios interesados de clasificación y memoria documental, como oportunamente recuerda, citando al Foucault de El orden del discurso, Delgado Gómez (2010, p. 117-133) y como sabemos por Dáder para el caso español.

\section{LA ESPECIALIZACIÓN PERIODÍSTICA}

Los editores de prensa viven hoy sobrepasados por la realidad que Internet y otros actuales vehículos de información, potencialmente globales, como el móvil, suponen como amenaza para los medios de comunicación tradicionales, y especialmente para el papel, es decir, para la prensa misma, y algunos creen que incluso para el periodismo, o sea, para la necesidad y capacidad humana de transmitir noticias e ideas de manera profesional y estructurada, así como para ejercer la crítica al poder que corresponde a toda sociedad verdaderamente democrática.

Sin embargo, en medio de esa angustia económica y "filosófica", en mitad de su desconcierto al no vislumbrar el futuro, muchas veces no se detienen a pensar que si la prensa tiene aún algún futuro es a través de la calidad y la especialización, y no intentando competir desesperadamente, imitando sus maneras, con otros medios irremediablemente más veloces y casi instantáneos. Lo que el papel (o en todo caso, el periodismo escrito, aunque no sea en papel) puede dar es una profesionalización y especialización mayor, junto al análisis y la contextualización de las noticias. Y en esta orientación, no sólo buena, sino imprescindible para su futuro y supervivencia, la documentación acude de nuevo en su auxilio de manera fundamental. La mayor precisión que una buena documentación facilita acerca al periodismo a sus ideales éticos y epistemológicos de veracidad y de registro científico de la realidad, respectivamente.

Como indica Moreno Matos (2006), “en la resolución de este reto, el documentalista de prensa ha sabido perfilar no sólo las habilidades inherentes a su profesión que los nuevos tiempos reclaman, sino que además ha redefinido sus funciones de modo tal que aporten un valor agregado a la información que antes era exclusividad de los periodistas. Nuevas funciones, nuevas habilidades, valor agregado".

Es pertinente la objeción de que el actual y generalizado acceso a Internet, también desde las salas de redacción periodísticas, haría casi innecesario el papel aquí reservado para los documentalistas. Eso sería así si pensásemos en estos profesionales como meros amanuenses o, como en los viejos tiempos, simples auxiliares de redacción. Pero aquí no nos estamos limitando a reconocer a los documentalistas el evidente papel técnico e instrumental que aportan $-\mathrm{y}$ ello incluso en la era de Internet- sino que intentamos reconocerle una labor categorial como registradores del verdadero conocimiento, papel que asumirían no desde las respectivas especializaciones (pues nadie es especialista en todo) sino como guía de alguien que, como el periodista, no es, necesariamente, 
especialista en nada, sino divulgador de ciertas realidades, incluida la divulgación de conocimientos especializados.

El documentalista debe aspirar a la verificación del ‘orden de lo verdadero' a través de las técnicas clasificatorias adquiridas durante su formación (técnicas sobre las que la epistemología no tiene nada que decir y por tanto nada diremos aquí), dilucidando, en el bosque moderno de datos, documentos e informes posibles con el que el periodista tropieza con frecuencia, qué es paja y qué es grano. Es más, Internet no sólo no convierte en innecesaria esa labor epistémica del documentalista, sino que la hace más necesaria para que los informadores no se pierdan en una selva de posibilidades difícil de manejar. Que sea o no utópico vindicar ese papel de la documentación resulta aquí intrascendente. Es como si dijéramos que resulta utópica la pretensión de los filósofos de ir a las cosas últimas y esenciales de la realidad, que sea o no humanamente realista esa pretensión no hace que los filósofos renuncien a ella. Y, desde luego, es técnicamente mucho más factible el papel que aquí pretendemos para los documentalistas que el "esencial" que para sí reivindican muchos filósofos.

\section{CONCLUSIONES}

La prensa posee valores éticos y epistemológicos homologables a cualquier otra actividad y es capaz de transmitir verdad como cualquier otra disciplina desarrollada con criterios científicos.

Para esta labor esencial de reflejo de la realidad social en su más extensa expresión, las herramientas de la documentación y de las tecnologías actuales de la información son garantía de un buen hacer profesional. Y son la base epistemológica fundamental -unida, claro, a la actitud ética y veraz de ambos profesionales- de la información.

Definitivamente, información periodística y documentación van a formar un par cognitivo inseparable en el presente y en el futuro, por lo que es necesario que los profesionales de ambas disciplinas adquieran plena conciencia de ello y que las empresas de comunicación acepten de forma plena la necesaria colaboración.

La aparición y uso extendido de Internet y de otras técnicas no invalida lo anterior. No se trata del dominio de nuevas herramientas y habilidades, con ser eso fundamental en el ejercicio de ambas profesiones, sino de esbozar una epistemología de la información, es decir, categorizar cognitivamente lo que estos profesionales presentan como verdadero, y en ese empeño lo que intentamos mantener aquí, en un primer esbozo, es que la documentación juega el papel de guía para reconocer el documento pertinente que avale lo afirmado por el periodista. El documentalista ya no es más un amanuense del periodista, sino que desde este nuevo estatuto de su labor pasa a ser el auténtico registrador de la verdad informativa. 


\section{BIBLIOGRAFÍA}

AGUADO TERRÓN, J.M. y MARTÍNEZ MARTÍNEZ, J.J. De la web social al móvil 2.0: el paradigma 2.0 en la comunicación móvil. El profesional de la información, 2009, vol. 18, p. 155-161.

CAPURRO, R. Epistemología y ciencia de la información. Enlace. Revista venezolana de Información, Tecnología y Conocimiento, 2007, año 4, nº 1, 2007, p. 11-29.

DÁDER, J.L. Periodismo de precisión. Vía socioinformática de descubrir noticias. Madrid: Síntesis, 1997.

DELGADO GÓMEZ, A. Documentos y poder; órdenes del discurso. Anales de Documentación, 2010, vol. 13, p. 117-133.

GONZÁLEZ ANTÓN, J. Canarias, en la documentación periodística en línea. Actas del I Congreso Internacional Latina de Documentación Social, 2009, Universidad de la Laguna (Tenerife) / SLCS, 2009.

HABERMAS, J. Historia y Crítica de la opinión pública. Barcelona, 1994.

KANT, I. Qué es la Ilustración, Madrid: Alianza Editorial, 2004.

LATORU, B. Ciencia en acción. Barcelona: Labor, 1992.

LINARES, R. "Epistemología y ciencia de la información: repensando un diálogo inconcluso". Acimed. Infomed, 2010, [En línea]. Disponible en <http://hdl.handle.net/ 10760/15105>. [Consulta: 10 de noviembre de 2011].

LIPPMAN, W. Public Opinión. New York, 1922.

LÓPEZ HERNÁNDEZ, A. La documentación, herramienta básica del periodista y del comunicador. Ámbitos, Revista Andaluza de Comunicación, Universidad de Sevilla, $2^{\circ}$ semestre, 2000, no 5, p. 129-142.

MEYER, P. Precision Journalism. A Reporter's Introduction to Social Science Methods, 1973. Edición en castellano: Periodismo de precisión. Nuevas fronteras para la investigación periodística. Barcelona: Bosch, 1993.

MORENO MATOS, J. Documentación y periodismo (o como crear valor periodístico desde la gestión de la información). Sala de prensa, 2006, n 88, año VII, vol. 3.

MOSCOSO, J. Objetividad y medida de la experiencia subjetiva consciente. Daimon, 2001, no 24, p. 127-137.

NICOLÁS, A. y FRAPOLLI, M.J. Teorías De la verdad en el siglo XX. Madrid, 1997.

PARRA PUJANTE, A. Periodismo y verdad. Filosofía de la información periodística. Madrid: Biblioteca Nueva, 2003.

PARRA PUJANTE, A. El estatuto epistemológico de la información periodística. Murcia: Universidad de Murcia, 2002.

TUCHMAN, G. La producción de la noticia. Estudio sobre la construcción de la realidad. Barcelona: Gustavo Gili, 1983.

TUCHMAN, G. La objetividad como ritual estratégico: un análisis de las nociones de objetividad de los periodistas. CIC. Cuadernos de Información y Comunicación, $\mathrm{n}^{\mathrm{o}} 4$, Madrid: Servicio de Publicaciones de la Universidad Complutense, 1999, nº 4, p. 199217. 